\title{
DESIGN OF PREDICTIVE CONTROLLER FOR SMOOTH SET POINT TRACKING FOR FAST DYNAMIC SYSTEM
}

\author{
Sumit G. Vyas ${ }^{1}$, Vinodkumar P. Patel $^{2}$ \\ ${ }^{I}$ Student of M.E., Instrumentation and Control Engineering, L.D. College of Engineering, Gujarat, India \\ ${ }^{2}$ Associate Professor, Instrumentation and Control Engineering, L.D. College of Engineering, Gujarat, India
}

\begin{abstract}
Model Predictive Control is generally used for slow dynamic system. Here efforts are made to implement MPC controller for Fast dynamic System. Speed control of DC motor is taken as fast dynamic system for which the MPC controller would be implemented. To control the speed of the DC motor Generalized Predictive Control (GPC) algorithm is used. In this paper, ARIX model based GPC control is implemented in 2-DOF structure. Transfer function of the DC motor is derived using LABVIEW and system identification tool of MATLAB. From the response of the system, it can be seen that the GPC has improved the performance of the system rather than PID control algorithm from disturbance rejection point of view.
\end{abstract}

Keywords: MPC (Model Predictive Controller), GPC (Generalized Predictive Controller), ARIX Model (Auto Regressive Integrated Exogenous Model).

\section{INTRODUCTION}

Model Predictive Controller requires large computation time. This time increases the delay in the system performance. So MPC controller gives better result for slow dynamic system. Another Problem of MPC is that there are so many theoretical solutions given by many researchers, but there is still more gap between practical implementation of MPC and theoretical solution given by researchers.

Here Speed control of DC motor has taken as fast dynamic system to validate the MPC controller algorithm. However PID and PI control are used for speed control of DC motor. PID control is one of the strategies that have been widely applied to industrial processes. Since it has superior features such as simple structure, good, robust, a precise mathematical model of the object is not required and obvious performance advance can always be obtained through partly improvement on PID algorithm. PI and PID are less effective to Set Point Tracking. So PI and PID control are very useful for constant load but if there are varying load or some other disturbance occurs then they are not useful so much.

Model Predictive Control (MPC) is also useful for speed control of DC motor. MPC is implemented in many Industrial Processes. History and research work for Model Predictive control is given in [1]. MPC can calculate the control law using either offline or online computing techniques. There are many techniques are used for calculation of control algorithm. Online Computation takes long time to calculate the control law while offline computation take a short time to calculate the control law.

MPC takes large computation time so it increases the settling time of system. That's why MPC is preferable for large dynamic system i.e. chemical process, oil refineries and petrochemical process. Now a days many researches try to reduce the computation time of MPC. In [2] MPC is implemented for PMSM motor, Generalized Predictive control applied for position control of Induction motor [3], Robust Model Predictive control for controlling the fast vehicle dynamic system is implemented [4]. All the above MPC has different control algorithm to each other regarding approximation, reducing the computation time etc.

In section II GPC control algorithm strategy is given, in section III Transfer function derivation procedure using MATLAB and LABVIEW is given. Section IV includes the simulation results of GPC for DC motor and comparison of GPC with PID controller.

\section{2. GENERALIZED \\ PREDICTIVE}

\section{CONTROLLER}

GPC is based on minimizing a weighted sum of the Set Point error and the control effort and it allows plant models to be updated frequently. GPC makes use of the j-step ahead prediction error model.

\subsection{J-Step Ahead ARIX Prediction Error Model:}

The ARIX model is referred as auto regressive integrated exogenous input model.

The ARIX model is given by the following equation:

$$
A(z) y(n)=z^{-k} B(z) u(n)+\frac{1}{\Delta} \xi(n)
$$

Where $\xi(n)$ is stands for random signals and $\frac{\xi(n)}{\Delta}$ denotes the random steps. Here $\Delta$ is the backward shift operator. 


$$
\begin{gathered}
\Delta(z)=1-z^{-1} \\
A(z)=1+a_{1} z^{-1}+a_{2} z^{-2}+\ldots \ldots \ldots+a_{d A} z^{-d A} \\
B(z)=1+b_{1} z^{-1}+b_{2} z^{-2}+\ldots \ldots \ldots+b_{d B} z^{-d B}
\end{gathered}
$$

After simplifying the equation (1) becomes

$$
y(n)=z^{-k} \frac{B(z)}{A(z)} u(n)+\frac{1}{\Delta A(z)} \xi(n)
$$

After separating the coefficient of the $\xi(n)$ into past and future terms we get the following equation

$$
\frac{1}{\Delta A(z)}=E_{j}(z)+z^{-j} \frac{F_{j}(z)}{\Delta A(z)}
$$

Degree of $E_{j}$ is j-1 and degree of $F_{j}$ is one less than that of $\Delta A$.

Multiply equation (3) by $z^{j} E_{j}$ we obtain

$$
z^{j} E_{j} \Delta A(z) y(n)=z^{j} E_{j} B \Delta u(n-k)+z^{j} E_{j} \xi(n)
$$

Substituting for $E_{j} \Delta A$ from equation (3)

$$
z^{j}\left(1-z^{-j} F_{j}\right) y(n)=E_{j} B \Delta u(n+j-k)+E_{j} \xi(n+j)
$$

Simplifying this we obtain the following,

$$
y(n+j)=G_{j} \Delta u(n+j-k)+F_{j} y++E_{j} \xi(n+j)
$$

As the degree of $E_{j}$ is $\mathrm{j}-1$ and $E_{j} \xi(n+j)$ has only terms of the form $\xi(n+i), \mathrm{i}>0$ that means only the future noise value.

$$
\hat{y}(n+j)=G_{j} \Delta u(n+j-k)+F_{j} y(n)
$$

Above equation is generalized $\mathrm{j}$ step ahead ARIX error prediction model.

\subsection{Generalized Predictive Control law for ARIX}

\section{Model}

It is desired that plant output follows a desired trajectory. As the plant has a delay of $\mathrm{k}$, the earliest time when the current input $u(n)$ can influence the output is $t+k$. As a result, it would like the plant output to follow a reference trajectory $\mathrm{w}$ from $\mathrm{t}+\mathrm{k}$ onwards.

As the noise is assumed to have steps we may not be able to constrain the absolute value of $u(n)$ but only change in it.

As we would expect the plant output to become constant and close to the set point after $\mathrm{N}$ intervals, we would like to have terms up to $\mathrm{t}+\mathrm{k}+\mathrm{N}$.
Thus the performance index is given by

$$
\begin{aligned}
& \quad J_{G P C}=[\hat{y}(n+k)-r(n+k)]^{2}+\ldots \ldots \ldots \\
& +[\hat{y}(n+k+N)-r(n+k+N)]^{2} \\
& +\rho[\Delta u(n)]^{2}+\ldots \ldots \ldots+\rho[\Delta u(n+N)]^{2}
\end{aligned}
$$

Using $\mathrm{j}$ step ahead prediction error model technique, predictive model for this plant is given by,

$\hat{y}(n+j)=G_{j} \Delta u(n+j-k)+F_{j} y(n)$

And $\quad G_{j}=E_{j}(\mathrm{z}) B(z)$

$E_{j}$ and $F_{j}$ are obtained by solving Aryabhatta's identity which is given in [5].

To express the performance index in terms of past values of $\mathrm{y}$ and $\mathrm{u}$ and future values of $\mathrm{u}$. The first term in eq (5) can be written as,

$$
\begin{aligned}
& G_{j} \Delta u(n+j-k)=g_{j, 0} \Delta u(n+j-k)+\cdots \\
& \quad+g_{j, d G_{j}} \Delta u(n-k+1-d B)
\end{aligned}
$$

Substituting for $\mathrm{j}=\mathrm{k}$ to $\mathrm{k}+\mathrm{N}$ and stacking them one below to the other we obtain the eq(5)

$$
\underline{\hat{y}}=G \underline{u}+H_{1} \underline{u}_{o l d}+H_{2} \underline{y}_{o l d}
$$

Where

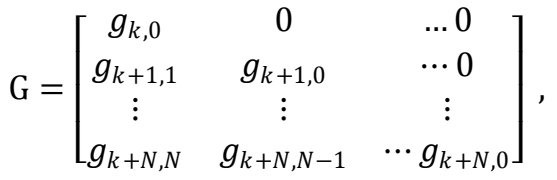

$$
\begin{aligned}
& H_{1}=\left[\begin{array}{ccc}
g_{k, 1} & \cdots & g_{k, d G_{k}} \\
g_{k+1,2} & \cdots & g_{k+1, d G_{k+1}} \\
\vdots & \vdots & \vdots \\
g_{k+N, N+1} & \cdots & g_{k+N, d G_{k+N}}
\end{array}\right], \\
& H_{2}=\left[\begin{array}{ccc}
f_{k, 0} & \cdots & f_{k, d A} \\
f_{k+1,0} & \cdots & f_{k+1, d A} \\
\vdots & \vdots & \vdots \\
f_{k+N, 0} & \cdots & f_{k+N, d A}
\end{array}\right] \\
& \underline{y}_{\text {old }}=[y(n) \ldots \ldots \ldots y(n-d A)]^{T}, \\
& \underline{u}_{o l d}=[\Delta u(n-1) \ldots \ldots . . . \Delta u(n-k+1-d B)]^{T}, \\
& \underline{u}=[\Delta u(n) \ldots \ldots \ldots \ldots \ldots . . . . . . . u(n+N)]^{T}, \\
& \underline{\hat{y}}=[\underline{\hat{y}}(n+k) \ldots \ldots \ldots \hat{\hat{y}}(n+k+N)]^{T}
\end{aligned}
$$

To minimize the error subtracting $r(n+j)$ from eq (9) then,

$$
\underline{\hat{y}}-\underline{r}=G \underline{u}+H_{1} \underline{u}_{o l d}+H_{2} \underline{y}_{o l d}-\underline{r}
$$


Now by solving $\underline{\hat{y}}-\underline{r}=0$, then above equation becomes,

$$
G \underline{u}=\underline{r}-H_{1} \underline{u}_{o l d}-H_{2} \underline{y}_{\text {old }}
$$

Controller output of GPC for ARIX model is given by,

$$
\underline{u}=k \underline{r}-k H_{2} \underline{y}_{o l d}-k H_{1} \underline{u}_{o l d}
$$

where $\underline{r}$ is a trajectory of reference signals.

$$
\begin{gathered}
\underline{r}=[r(n+k) \ldots \ldots \ldots \ldots r(n+k+N)]^{T}, \\
k=\left(G^{T} G\right)^{-1} G^{T},
\end{gathered}
$$

It is assumed that the error signal and the control signal effort are weighted over the same length of time as shown in eq (6) in which both terms are weighted over $\mathrm{N}+1$ intervals.

However, the control effort is usually weighted over interval that means $\mathrm{u}$ becoming a constant sooner than $\mathrm{k}+\mathrm{N}$ intervals in eq(6). Now generalizing this situation by minimizing the error from $n+k+N 1$ to $n+k+N 2, N 2 \geq N 1$ and the control effort from $\mathrm{n}$ to $\mathrm{n}+\mathrm{Nu}$.

The performance index is given by eq(6) becomes

$$
\begin{aligned}
J_{G P C}= & {\left[\hat{y}\left(n+k+N_{1}\right)-r\left(n+k+N_{1}\right)\right]^{2}+} \\
& \ldots \ldots \ldots+\left[\hat{y}\left(n+k+N_{2}\right)-r\left(n+k+N_{2}\right)\right]^{2} \\
+ & \rho[\Delta u(n)]^{2}+\ldots \ldots \ldots+\rho\left[\Delta u\left(n+N_{u}\right)\right]^{2}
\end{aligned}
$$

As a result of this $\underline{\hat{y}}$ and $\underline{u}$ given by

$$
\begin{gathered}
\underline{\hat{y}}=\left[\underline{\hat{y}}\left(n+k+N_{1}\right) \ldots \ldots \ldots \underline{\hat{y}}\left(n+k+N_{2}\right)\right]^{T} \\
\underline{u}=\left[\Delta u(n) \ldots \ldots \ldots \ldots \ldots . \Delta u\left(n+N_{u}\right)\right]^{T}
\end{gathered}
$$

The performance of the GPC depends on the parameters N1, $\mathrm{N} 2, \mathrm{~N}_{\mathrm{u}}$ and $\rho$. So the proper selection of these parameters gives better results. Tuning of these parameters is necessary and which is given in the [5], [6] and [7]. More detail on GPC controller is given in [5].

\section{DC MOTOR}

For the case study of the above algorithm DC motor system is used. However, the Model Predictive Control gives good performance for slow dynamic system i.e. chemical processes, petrochemical processes, oil and refineries but it is not useful for slow dynamic system i.e. robotics, automation, power electronics, etc. Therefore DC motor is used to check the validity of above algorithm.

\subsection{Motor Specification:}

Fig(1) show the DC motor which I have used.

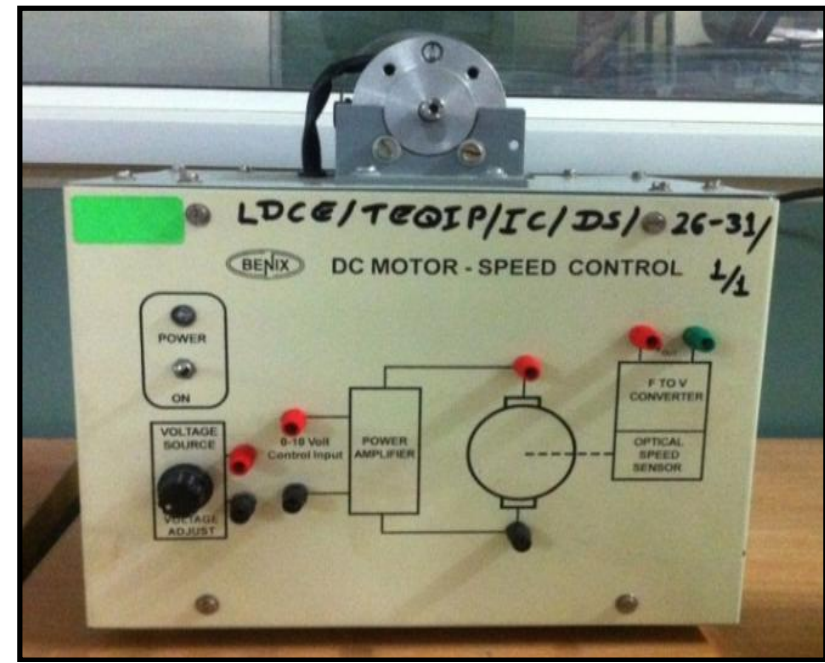

Fig- 1: DC motor

\section{- Specifications:}

1. Maximum speed: $1500 \mathrm{Rpm}$

2. Maximum input Voltage: $10 \mathrm{~V}$ DC

3. Maximum input Current: 0.9Amp

4. F to V converter output: 0 to 2 volt for 0 to 1500 rpm.

\subsection{System Identification:}

System identification uses the statistical methods to build the mathematical model of the dynamics system from measured data. Data Acquisition of the DC Motor is done by LABVIEW at the sampling time of $0.001 \mathrm{sec}$. After trying different pole - zero combination different transfer functions are estimated. The estimated transfer function also shows how many percentages match with actual transfer function.

In figure (2) input signal given to motor and motor's output waveform are shown. According this test signal and using System Identification toolbox of the MATLAB the estimated model output of the DC motor is shown in figure(3).

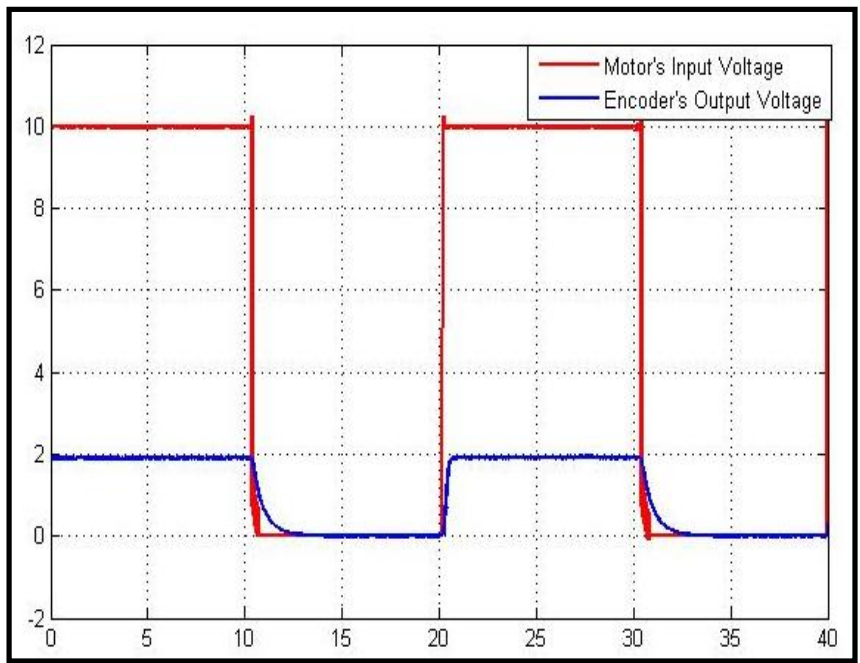

Fig- 2: Input and Output response of measured data of DC motor 


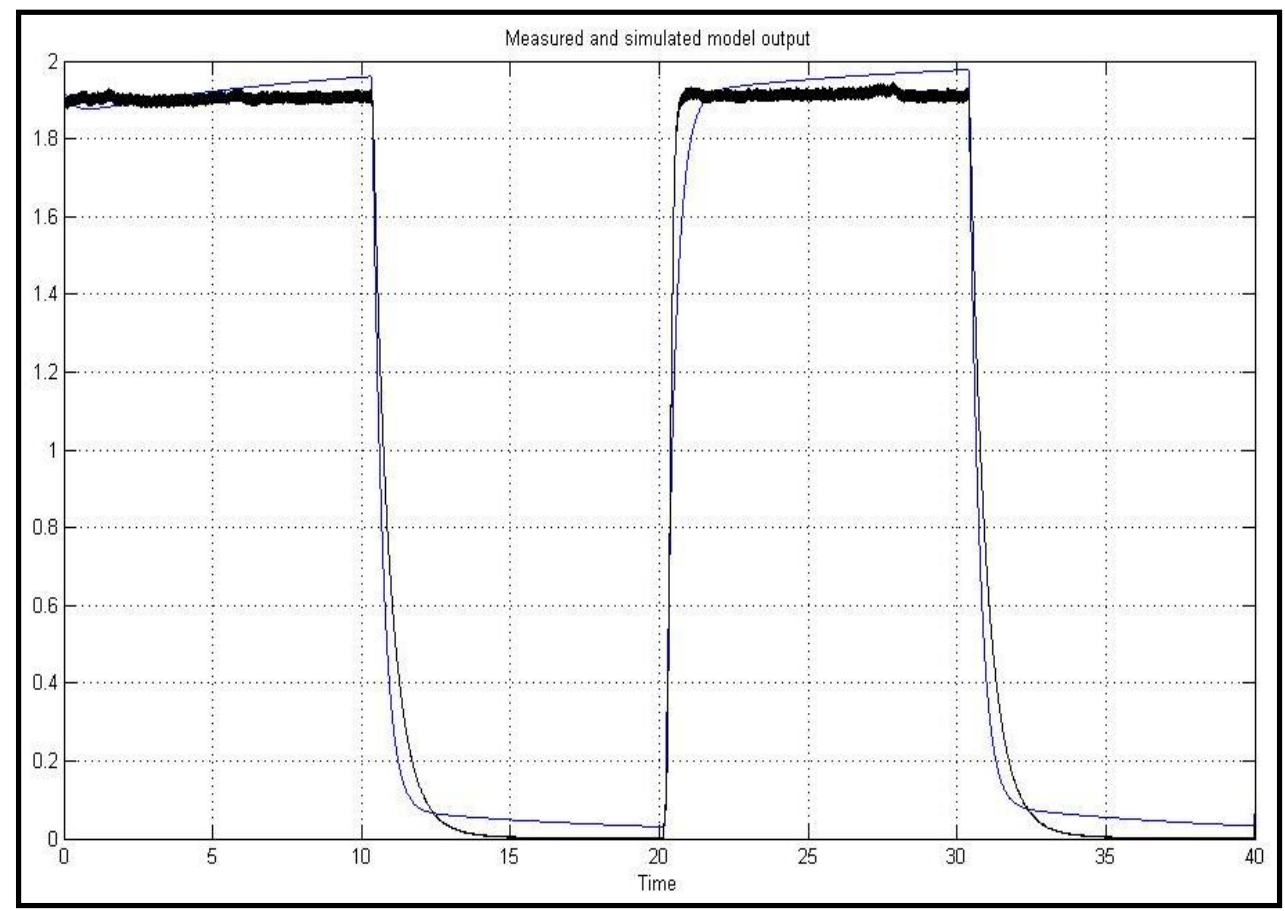

Fig- 3: Response of Measured data and Simulated Model of DC motor

The Estimated model of the DC motor is as given below,

$$
G(S)=\frac{0.5957 S+0.0683}{S^{2}+3.248 S+0.339}
$$

With one zero and two pole and the estimated transfer function fits the data by $89.54 \%$.

Transfer function of DC motor in $\mathrm{Z}$ domain is given as below,

$$
G(z)=\frac{0.0321 \mathrm{z}-0.03187}{\mathrm{z}^{2}-1.825 \mathrm{z}+0.8256}
$$

\section{SIMULATION RESULTS}

In this section result comparison of GPC controller with discrete time PID controller is shown. First of all PID tuning was done using Good Gain method. More detail about Good Gain Method is given in [8]. From the figure (2) settling time of system in open loop response is $0.59 \mathrm{sec}$ so here I have taken sampling time $\mathrm{Ts}=0.059 \mathrm{sec}$.

\subsection{Motor's Response without Disturbance:}

Motor's closed loop response with PID controller and GPC controller is show in figure (4). In this response no disturbance is given.

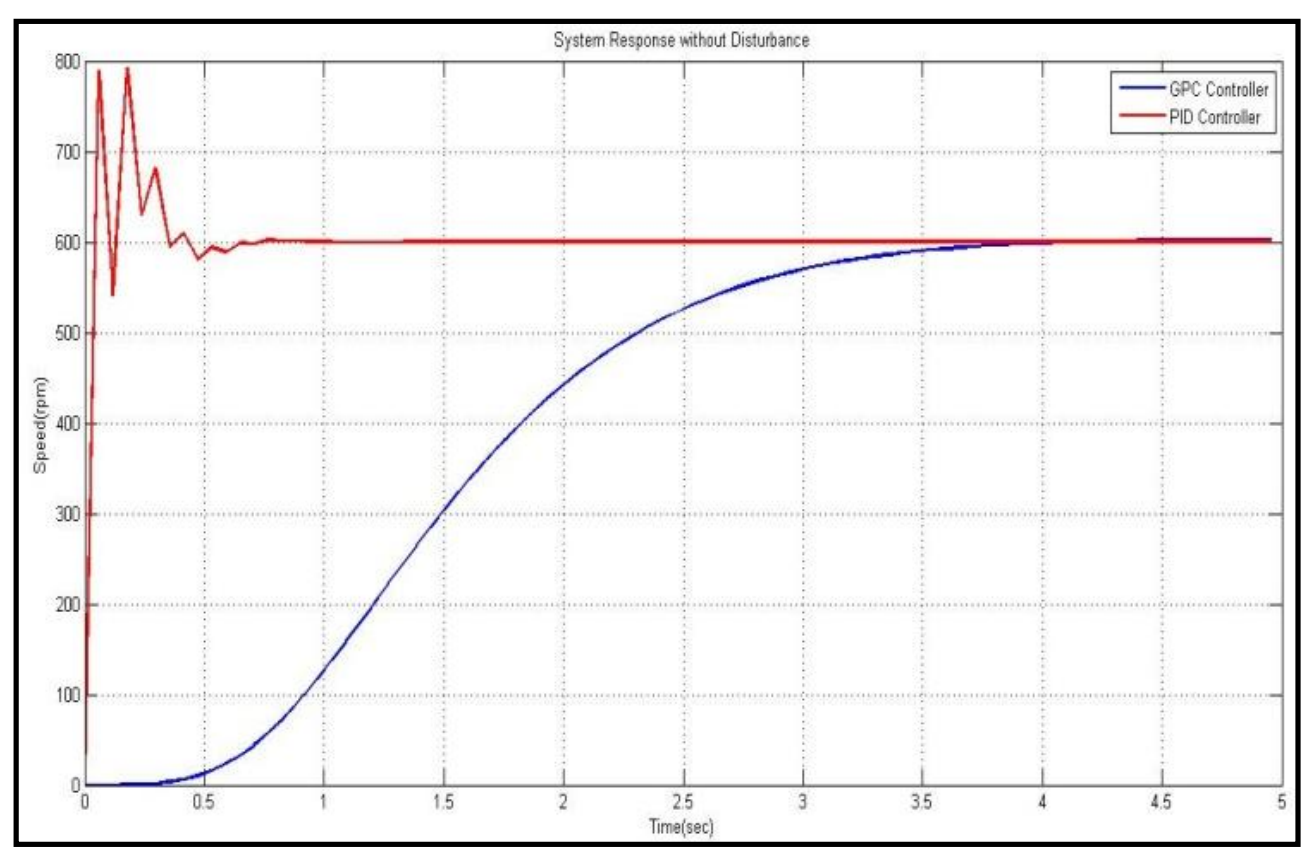

Fig-4: System Response without Disturbance 


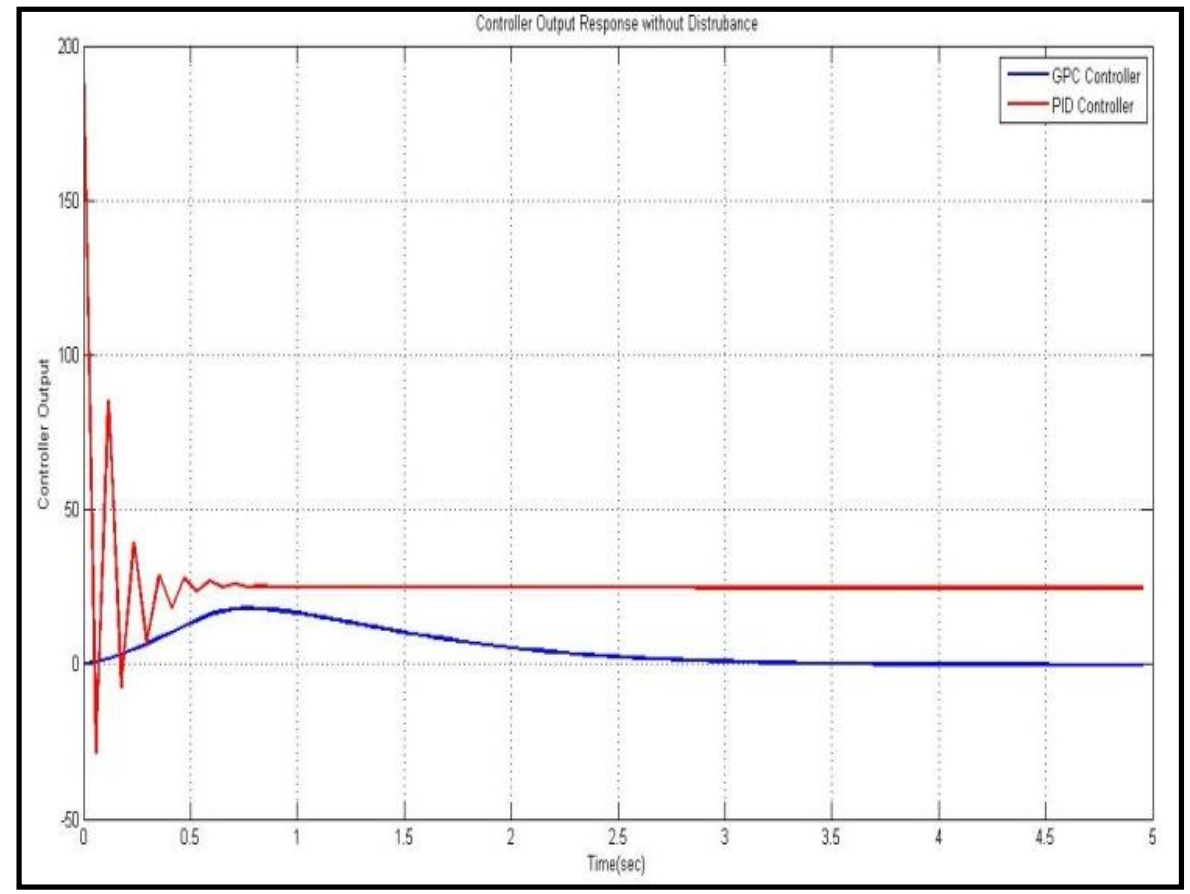

Fig-5: GPC and PID controller output without Disturbance

Figure 5 shows the both GPC and PID controller output response without Disturbance. Here set point is $600 \mathrm{rpm}$ taken for closed loop response and PID controller have approximately $32 \%$ overshoot while GPC controller has approximately $0.42 \%$ overshoot. From overshoot perspective GPC is better than PID controller but for settling point perspective PID have good response than GPC because PID has settling time of $1 \mathrm{sec}$ while GPC has settling time of $5 \mathrm{sec}$.
In this result step change as disturbance is applied at time 10 sec both controller rejects the disturbance effectively which is shown in following figures.

From controller output response PID controller has initially large peak than GPC controller and PID rejects the disturbance fast but oscillation occurs in the output while GPC rejects the disturbance slowly but there is no oscillation in the response.

\subsection{Motor's Response with Disturbance:}

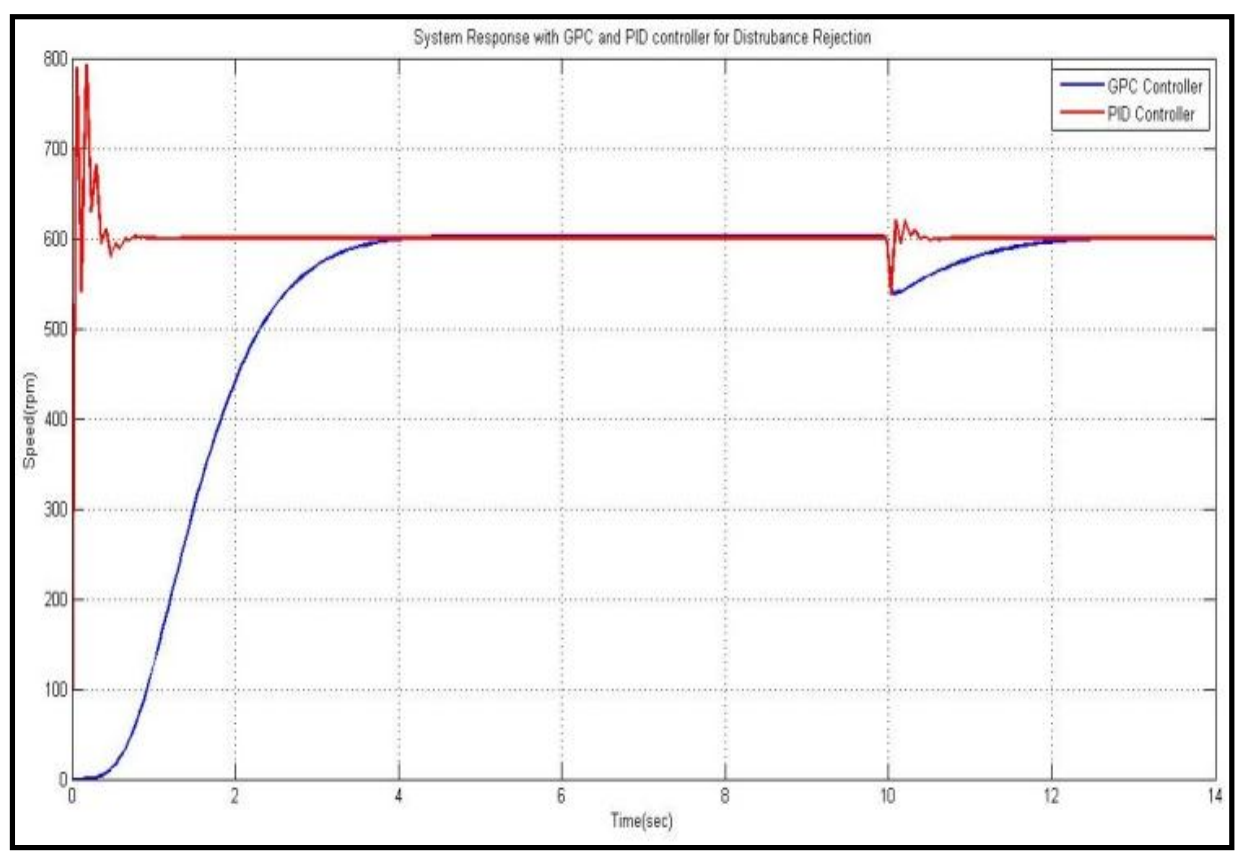

Fig-6: System Response for Disturbance rejection 


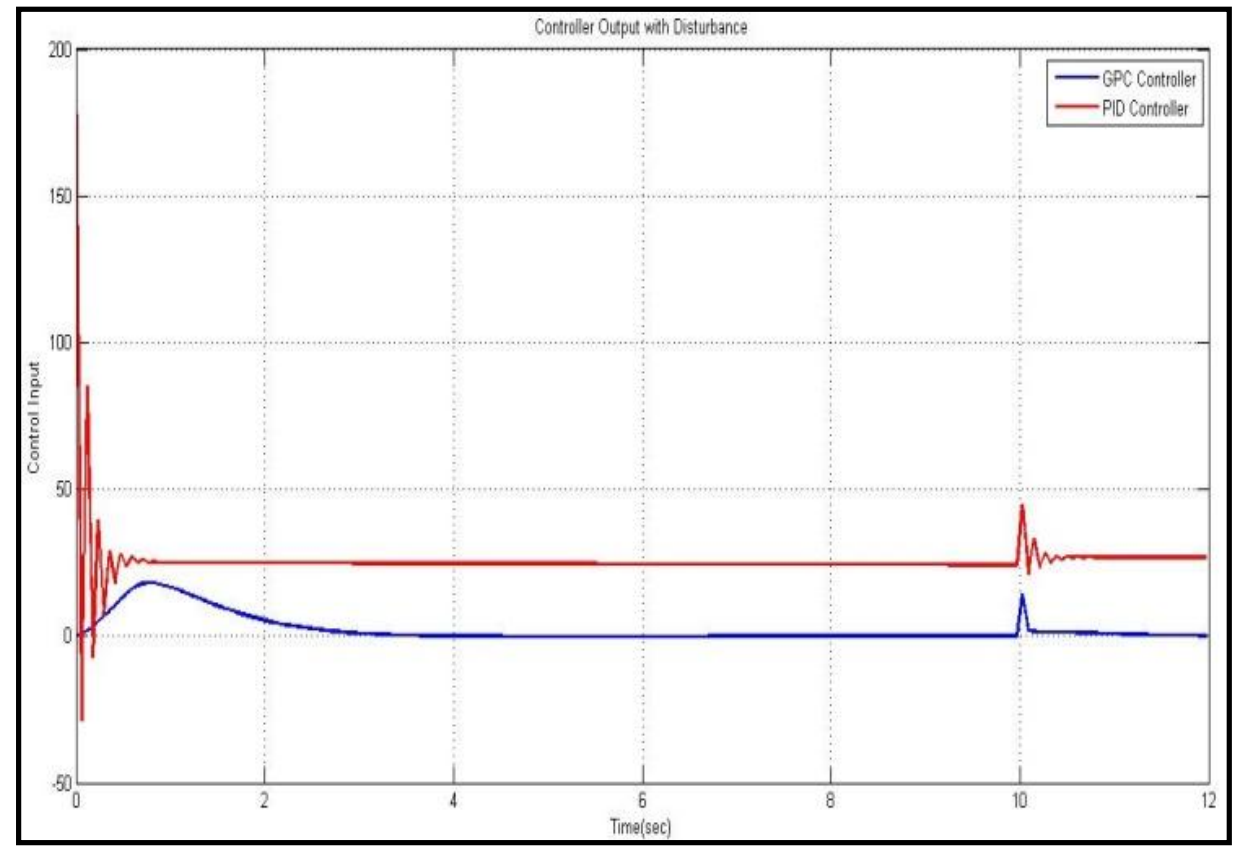

Fig-7: GPC and PID controller output for Disturbance Rejection

\subsection{Set Point Tracking Results of DC Motor:}

These results are shown for the case where continuous changes in the Set point are occurs. From set point tracking perspective, GPC controller has smooth tracking than PID controller. so GPC controller can be used where overshoot is major problem than settling time. Here results of GPC and PID controller for DC motor speed control is shown in following figures.
From the above response GPC controller has good response then PID controller for set point tracking. Settling time of GPC controller is more than PID controller because GPC controller has complex computation than PID controller, so if computation bourdon or Computation time of GPC controller is reduced than settling time may be improved

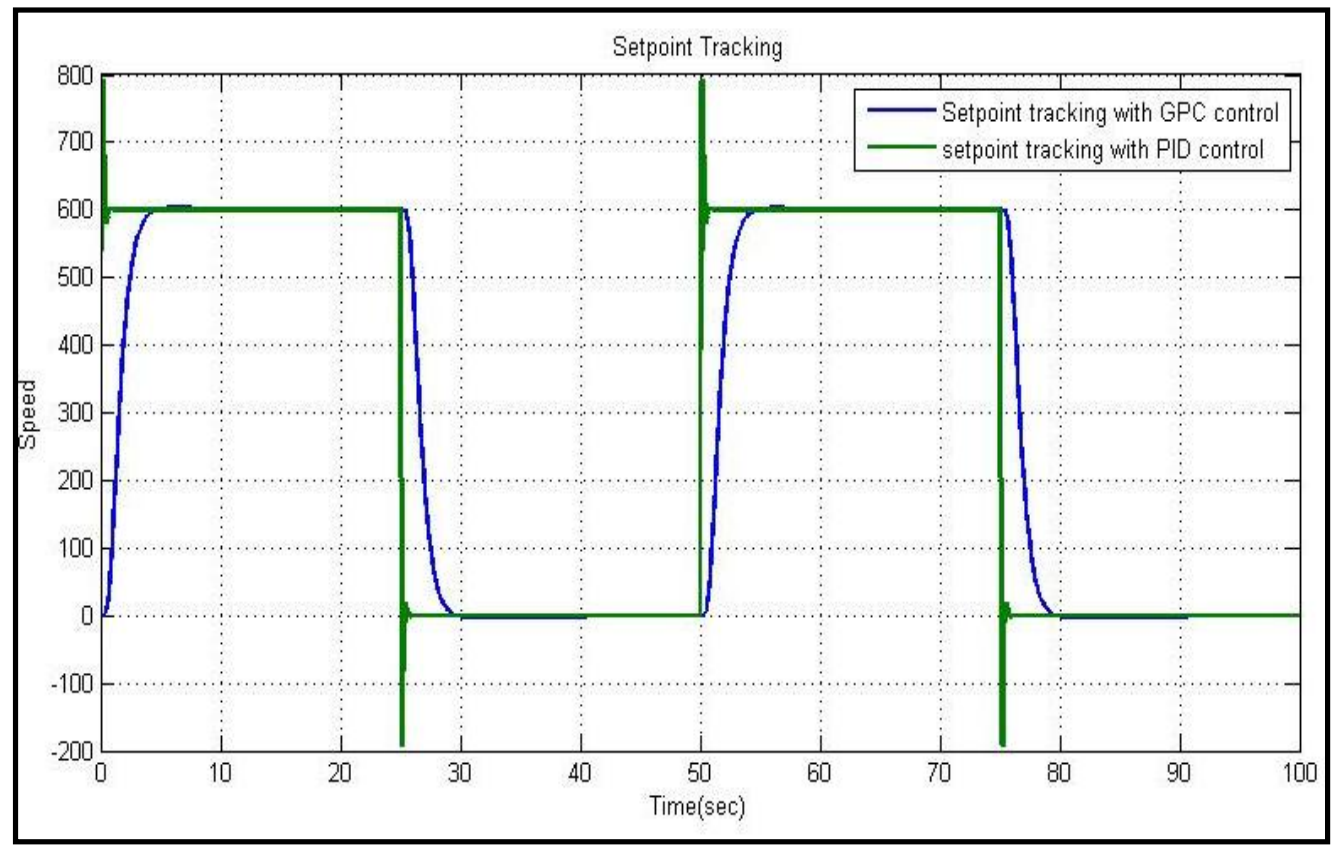

Fig-8: System Response for Set Point Tracking 


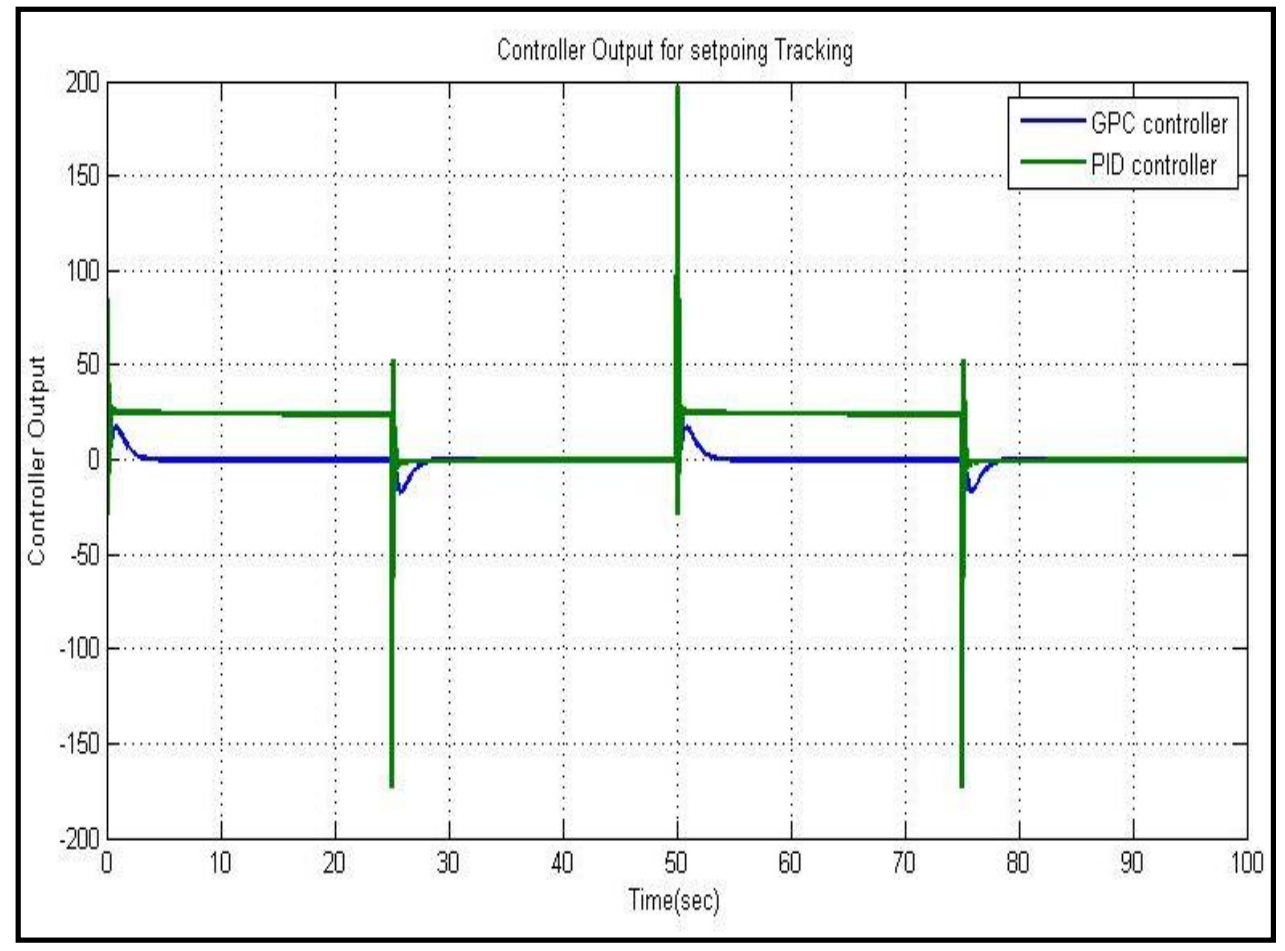

Fig- 9: GPC and PID controller Output for Set Point Tracking

Comparison of PID and GPC controller is given in following table form the above simulation results

Table-1: Comparison Results of GPC and PID Controller

\begin{tabular}{|l|l|l|l|l|}
\hline & \multicolumn{2}{|l|}{ GPC } & \multicolumn{2}{l|}{ PID } \\
\cline { 2 - 5 } & $\begin{array}{l}\text { Over } \\
\text { shoot } \\
(\%)\end{array}$ & $\begin{array}{l}\text { Settling } \\
\text { Time } \\
(\mathrm{sec})\end{array}$ & $\begin{array}{l}\text { Over } \\
\text { shoot } \\
(\%)\end{array}$ & $\begin{array}{l}\text { Settling } \\
\text { Time } \\
(\mathrm{sec})\end{array}$ \\
\hline $\begin{array}{l}\text { Disturbance } \\
\text { Rejection }\end{array}$ & 0.42 & 5 & 32.17 & 1 \\
\hline $\begin{array}{l}\text { Set Point } \\
\text { Tracking }\end{array}$ & 0.42 & 5 & 32.17 & 1 \\
\hline
\end{tabular}

\section{CONCLUSION}

From the results shown above it is concluded that the Generalized Predictive Controller gives the stable and smooth response than the PID Controller. The Major Drawback of GPC is that it takes more time to settle down at Set Point value this is because of large computation burden and it is time consuming algorithm. The main advantage of GPC over PID controller is that it has no overshoot and smooth tracking in system for varying Set Point. It has a $0.42 \%$ overshoot in system response while PID controller have $32 \%$ Overshoot and settling time of GPC is $5 \mathrm{sec}$ while settling time PID controller based system response has $1 \mathrm{sec}$ only.

\section{REFERENCES}

[1] Yu-Geng Xi, De-Wei, Shu LIN, "Predictive Control - Status and Challenges" Vol.39, No.3, Acta Automatica Sinica, ScienceDirect, March -2013.
[2] Gionata Cimini, Valentino Fossi, Gianluca Ippoliti, Stefano Mencarelli, Giuseppe Orlando and Matteo Pirro, "Model Predictive Control Solution for Permanent Magnet Synchronous Motors", Industrial Electronics Society, IECON 2013, IEEE.

[3] Antonio B.S.Junior, Francisco G. Sena, Bismark C. Torrico, Luiz H.S.C. Barreto,"Generalized Predictive Control Applied to the Position Control of a Induction Motor", Industry Application, IEEE, 2012.

[4] T. Peni, J. Bokor, "Robust Model Predictive Control for Controlling Fast Vehicle Dynamics", Control and Automation 2006, IEEE.

[5] "Digital Control” by Kannan Moudgalya.

[6] "Model Based Predictive Control of Electrical Drives" by Arne Linder, Rahul Kanchan, Ralph Kennel, Peter Stolze.

[7] Junxia $\mathrm{Mu}$ and David Rees, "Approximate Model Predictive Control for Gas Turbine Engines", Proceeding of the 2004 American Control Conference, June-July 2004.

[8] "The Good Gain Method for PI and PID Controller Tuning" by Finn Haugen.

[9] "Model Predictive Control" by Eduardo F. Camacho and Carlos Bordons.

[10] Yang Su, Kok Kiong Tan, Tong Heng Lee, "Computation Delay Compensation for real time implementation of robust model Predictive Control", Journal of Process Control, ELSEVIER,2013.

[11] Vihangkumar V. Naik, D.N. Sonawane, Deepak D. Ingole and Divyesh Ginoya, "Model Predictive Control of DC servomotor using Active Set Method", IEEE Multi-Conference on Systems and Control, IEEE, 2013. 
[12] S. Joe Qin, Thomas A. Badgwell, "A Survey of Model Predictive Control Technology", Control Engineering Practice, Science Direct, 2003.

[13] Mark L. Darby, Michael Nikolaou, "MPC: Current Practices and Challenges", Chemical Engineering Practices, 2012.

[14] "PID Controller: Theory, Design and Tuning" by K. Astrom and T. Hugglund. 